\title{
関節トルクフィードバックによる減速機付き ロボットアームの運動制御
}

\author{
橋 本 稔* \\ Motion Control of Robot Arms with Reducers Based on Joint Torque Feedback
}

Minoru Hashimoto*

Since the dynamic equation of robot arms represents a nonlinear and time-varying system, it is difficult to control precisely the manipulator when it moves with high speed and heavy load. In order to solve this problem there have been proposed many control schemes with compensating the dynamic effects involving dynamic interaction between joints. However, it is not easy to compute the inverse dynamics in real time. To reduce the computational burden, many authors have derived various computational schemes of the inverse dynamics.

In the present paper, we propose to introduce a torque sensor for each joint, instead of the computation, to measure the torque generated by the dynamic effects. The advantage of this technique is that the computational load is reduced much and the control system becomes robust for unexpecting external disturbance such as gravity acting on objects picked up and put down or other interactions with the environment. Therefore, this control scheme could be useful to the precise and robust control of the robot manipulators. We introduce dynamic modeling and stability analysis of the joint torque feedback control for robot arms with reducers in the drive trains. Furthermore, we will show the experimental results for a two joints arm which prove the validity of the control technique.

Key Words: robot control, torque sensor, dynamic control, manipulator, robot arm

* 電気通信大学 調布市調布ケ丘 1-5-1

* University of Electro-Communications, Chofu (Received June 6, 1988)

(Revised September 26, 1988)

\section{1.はじめに}

ロボットアームは, リンク間の動的干渉, 慣性変 動, 手先に物体を把持したときの負荷の変動などロ ボットの運動中にさまざまな外乱や変動を生じるため に，その制御は定慣性定負荷のサーボ機構にはない特 殊性をむっている．そのため一般に産業用ロボットな どでは，高ゲインフィードバックによりできる限り各 関節のサーボ剛性を上げるととにより，それらの外乱 や変動の影響を少なくする方法がとられている．しか し，それであなお高速または高負荷荷重の場合その位 置制御性が悪くなるという問題や，高ゲインであるた めに効率が悪い，制御系が不安定になりやすいなどの 問題が存在する.

このような問題を解決するために，計算トルク 法1),2), 非線形フィードバック制御3)な゙さまざまな 制御法が考案されてきたが，それらを実際のロボット アームの制御に適用するためには, 多くの実時間計算 を必要とし，いかに計算量を減らすかということが一 つの重要な課題とされてきだ),5).

一方，最近，ロボットアームを関節間の干渉や非線 形性を含む多入力多出力系と考えるのではなく, 口ボ ットの各関節に着目して, 動力学的干涉や負荷変動に より各関節に作用するトルクをセンサにより測定し， それをフィードバックするととにより補償しようとい う制御法が Kirkansky ${ }^{6)}$ と小菅ら7により提案された. この制御法の特徴は,

(1) 動力学的干渉項や把持物体などによる負荷を推 定することなくそれを補償する運動制御ができ るとと,

(2) トルクセンサとして用いられるストレインゲー ジが安価で, サーボ系の構成が容易であること である。

小菅らは，この方法により二関節ダイレクトドライブ 
アームを制御し，関節トルクセンサ情報をフィードバ ックするととにより，位置制御性が向上するととなど を示した．同時に彼らは，トルクセンサにより測定さ れるトルクは，ロボットアームの動的干渉によって各 関節に作用するトルクの一部であって，各関節が空間 中を運動する際のモータに加わる慣性力が含まれてい ないこと，それを知るためには直交座標系における各 関節の位置および速度を計算する必要があるととを指 摘している. しかしての計算のためにはニュートンオ イラー法における一巡計算の台座側から手先に向かう 計算を必要とし，実時間計算削減の障害となるものと 思われる.

この問題を解決する一つの方法は，モータを台座に 固定し，リンクのみを適当なトルク伝達機構を介して 駆動させるような機構を構成することである. この方 法によれば，モータ自身が空間中を運動するととによ る慣性力はゼロとなり，乙のための計算はまったく必 要なくなる，しかし一方，乙の方法では，多自由度化 にともない機構が複雑となり，また特殊な機構のロボ ットアームでなりればこの制御法を適用できないとい う問題が生じる.

筆者らは，減速機付きロボットアームの場合，ての モータに加わる測定不可能なトルクが減速比に比して 減少し，その位置制御性への影響がきわめて小さいと とに着目して, より現実的な方法として, 従来の補償 要素とトルクセンサフィードバックによってのみ構成 される位置サーボ機構を提案したい. との方法によれ ば，動的干渉によるトルクの 1 次成分を補償すること ができるし，把持物体の負荷変動に対してはモータの 飽和限界内で完全に無反応化することができ, 理想的 な位置サーボ剛性を得ることができる，本論文の目的 は，このような制御系のモデルを示すとともに，その 安定性について考察し，本制御法の特徵を実験的に検 証するととである。

なお，本制御法は，大梘ら8)によるいわゆる「負荷 無反応形電気サーボ機構」をより安定なサーボ機構と して発展させたすのと考えられる. 負荷無反応型サー ボ機構は負荷系による外乱トルクのみならずモータ発 生トルクをあ含む系全体のトルクを電流などのフィー ドバックループにより無反応化させようとするあの で，その安定性が保たれる領域がきわめて制限される などの問題がある．乙れに対して本制御法は，負荷系 による外乱トルクのみをトルクセンサで検出しフィー ドバックすることにより，ロボットアームの複雑な動 力学を補償して, 単なるモータ系の制御問題に帰着さ せようというもので, 後述するように安定な領域がよ
り広くなるという特徽がある.

また，最近，動的非線形干渉項を直接測定するので はなく，入力トルクと関節角加速度から推定しようと いう研究9) 111や，加速度を直接制御するととにより負

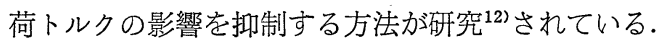
これらの方法は，前述したような測定できない動的干 渉要素がないという利点がある反面, 加速度推定にお けるノイズと推定時間遅れが問題となるものと思われ る.ロボットのように不連続的な負荷変動を伴うシス テムの場合，時間遅れなく正確に状態を推定すること はロバストな制御を実現する上で重要な課題であ る ${ }^{13)}$.

本論文ではまず，ロボットアームの各関節に着目し た力学モデルを示し，関節トルクセンサにより測定不 可能なトルクの位置制御への影響を考察する，第 3 章 では,トルクセンサフィードバックを含んだサーボ機 構のモデル化とその閉ループ安定性について議論され る. 第 4 章では試作システムによる制御実験の結果を 示し，本サーボ機構の有効性を示す.

\section{2. 関節のカ学モデル}

ロボットアームの各関節における動力学をことでは Fig. 1 のようにモデル化する.トルクセンサの位置を 境としてモータと台座側のリンクにより構成されるモ 一タ系とそのモータよりあ手先の側にあるすべてのリ ンクおよび関節によって構成される系とに分けること ができる．モータ系の慣性 $J_{\boldsymbol{m}}$ および粘性摩擦 $B_{\boldsymbol{m}}$ は 一定と仮定し, リンク系のそれら $J_{l}, B_{l}$ は他の関節 角の変化などにより変動するあのとする．T、はこの 関節から手先までのリンクによる動的干渉力および重 力，把持物体による負荷などの和である． $T_{m}$ はモー タが発生するトルクであり，乙れはモータの電流を制

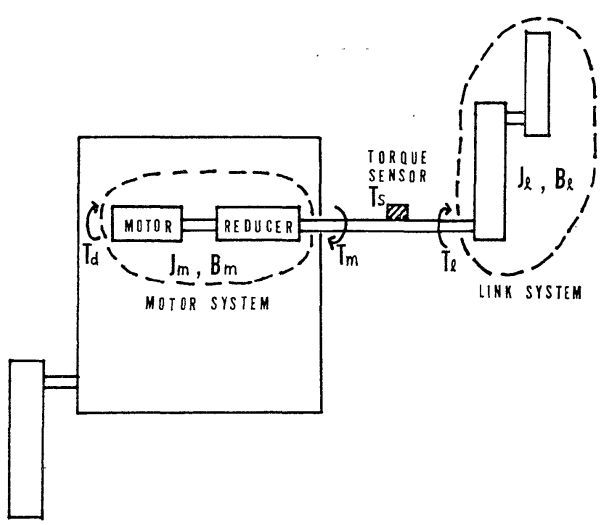

Fig. 1 Schematic drawing of the joint model 
御するととにより制御できる．さらに $T_{d}$ は，乙の関 節のロータおよび減速機が空間を運動するために生ず る慣性力である．ここで， $T_{m}, T_{d}$ は実際にこの位置 に作用するトルクに減速比 $n(<=1)$ の逆数を乗じて 関節座標系に変換してあるとし, 同様に $J_{m}, B_{m}$ 屯関 節座標系で表わされているとすると, 乙の系の運動方 程式は (2.1)式のような簡単な形で表わすととがで きる.

$$
T_{m}+T_{d}+T_{l}=\left(J_{m}+J_{l}\right) \ddot{q}+\left(B_{m}+B_{l}\right) \dot{q}
$$

ここで, $\dot{q}, \ddot{q}$ は着目している関節の角速度および角 加速度を表わしている. トルクセンサにより測定され るTsは，七ンサ位置における釣合条件よりつぎのよ うになる。

$$
T_{s}=-T_{l}+J_{l} \ddot{q}+B_{l} \dot{q}
$$

(2.2)式より，(2.1)式はつぎのようなモータ系の負荷 のみを用いた式に変換される.

$$
T_{m}+T_{d}-T_{s}=J_{m} \ddot{q}+B_{m} \dot{q}
$$

モータへの制御入力として目標角からの偏差を補償す るためのトルク $T_{c}$ をむちいて，

$$
T_{m}=T_{c}+T_{s}
$$

とするならば，制御システムはつぎの式で表わされ る.

$$
T_{c}=J_{m} \ddot{q}+B_{m} \dot{q}+T_{d}
$$

したがって，ロボットアームの動的干渉を含む複雑な 制御系を各モータ系に分離された制御問題として扱う ことができる．乙こで $T_{d}$ はトルクセンサによって測 定できないので外乱トルクとして扱われる.

このトルク $T_{d}$ の位置制御性への影響を考察するた めにモータ系の運動方程式をオイラー法により記述し てみる. いま, 第 $i$ 関節軸上に原点があり, $z$ 軸がそ の関節軸と一致する座標系を設定し, その $z$ 軸方向の 単位ベクトルを $z_{i-1}$ とすると,

$$
\begin{aligned}
\tau_{d i}= & \boldsymbol{z}_{i-1}^{T}\left[\boldsymbol{I}_{m i} \dot{\boldsymbol{\omega}}_{i-1}+\boldsymbol{I}_{m i}\left[\boldsymbol{\omega}_{i-1} \times\left(\boldsymbol{z}_{i-1} \dot{q}_{i} / n\right)\right]\right. \\
& \left.+\boldsymbol{\omega}_{i}^{\prime} \times\left(\boldsymbol{I}_{m i} \boldsymbol{\omega}_{i}^{\prime}\right)\right]
\end{aligned}
$$

ここで，下付き添え字 $i$ は台座側から数えた関節の 番号を示し, 上付きの $T$ は行列の転置を表わしてい る. $\omega_{i-1}$ は絶対座標系における第 $i-1$ リンクの角速 度で, $\omega_{i}^{\prime}$ は第 $i$ ロータの角速度であり次式によって 表わされる.

$$
\omega_{i}^{\prime}=\omega_{i-1}+z_{i-1} \dot{q}_{i} / n
$$

また， $\boldsymbol{I}_{m}$ はアクチュエータ座標系で示された慣性行 列である. $\tau_{d i}$ はアクチュエータの座標系で示されて おり，とれをリンク座標系へ変換すると，

$$
T_{d i}=\tau_{d i} / n
$$

いま，Fig. 2 のようにモー夕系の質量中心が $z$ 軸上 にあり， $z$ 軸に関して回転対称であるようなモデルを

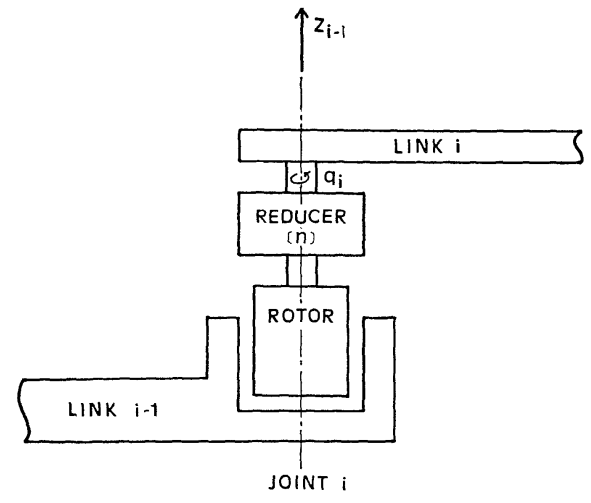

Fig. 2 Coordinate system of a joint

考えると，上式はつぎのように簡単に表わされる。

$$
T_{d i}=n J_{m} \boldsymbol{z}_{i-1}^{T} \dot{\boldsymbol{\omega}}_{i-1}
$$

いま比較のために，リンク系がこの $\dot{\boldsymbol{\omega}}_{i-1}$ の運動をす るために要するトルク $T_{l}^{\prime}$ を見積ると，

$$
T_{l i}^{\prime}=J_{l} \boldsymbol{z}_{i-1}^{T} \dot{\boldsymbol{\omega}}_{i-1}
$$

となる、インピーダンスマッチングがとれていて， $J_{m}$ と $J_{l}$ が等しい場合を考えると，(2.9)，(2.10)式よ りつぎの関係が得られる.

$$
T_{d}=n T_{l}^{\prime}
$$

一般のロボットマニピュレータでは, $n$ として $1 / 50$ 程度が使われているから，モータ系が空間中を運動す ることによる慣性トルク $T_{d}$ は，リンク系のそれ $T_{i}^{\prime}$ に比べ無視できるほよ゙小さいととになる，T渷節 トルクセンサにより測定されるために，測定不可能な トルク $T_{d}$ による位置制御性への影響はきわめて小さ いもの之思われる.

\section{3. サーボ機構の安定性}

(2.1)〜 (2.5)式にしたがってトルクセンサフィード バックを含むサーボ系のブロック線図を書くと Fig. 3 (a)のようになる. $K_{t}$ はトルクセンサのフィードバ ックゲインである.いま, 関節角の目標值を $Q_{d}$, 外乱 トルク $T_{d}$ と $T_{l}$, 制御量を $Q$ としたときにつぎの 関係が得られる。

$$
\begin{aligned}
& \left\{G_{m} s+K_{t}^{\prime} G_{l} s+G_{b} K_{b} s / K_{e}+K_{a} G_{c} G_{b}\right\} Q \\
& \quad=K_{a} G_{b} G_{c} Q_{d}+T_{d}+K_{t}^{\prime} T_{l}
\end{aligned}
$$

ここで, $K_{a}$ は増幅ゲイン, $K_{b}$ は逆起電力定数であ る. $G_{b}$ は電機子電圧加ら出力トルクへの伝達関数で (3.2)式のようであり，そのブロック線図を Fig. 3 (b)に示してある.

$$
G_{b}=K_{e} K_{f} /\left(L s+R+K_{e} K_{g}\right)
$$

ここで, $L$ は電機子インダクタンス， $R$ は電機子抵 抗， $K_{e}$ は増幅ゲイン， $K_{0}$ は電流フィードバックゲイ 


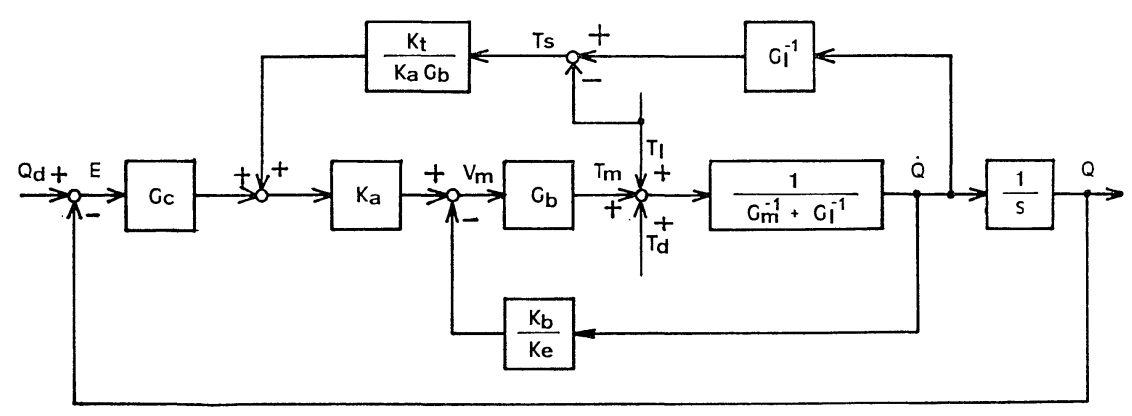

(a) Total system

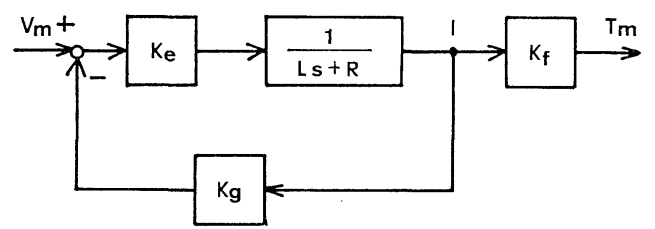

(b) Part $\mathrm{Gb}$ in the system

Fig. 3 Block diagram of the servo system

ン， $K_{f}$ はトルク定数である. また， $G_{m}, G_{l}$ はそれ ぞれモータおよびリンク系の負荷の逆数を表わし， $G_{c}$ は位置補償要素でここでは PD 制御（比例ゲイン： $K_{p}$, 微分ゲイン $\left.: K_{d}\right)$ を用いている.

$$
\begin{aligned}
G_{m} & =1 /\left(J_{m} s+B_{m}\right) \\
G_{l} & =1 /\left(J_{l} s+B_{l}\right) \\
G_{c} & =K_{p}+K_{d} s
\end{aligned}
$$

$K_{t}^{\prime}=1-K_{t}$ であり, $K_{t}^{\prime}=1$ であれば, トルクセン サフィードバックのない制御系を表わし， $K_{t}^{\prime}=0$ とす ると以下のように $G_{l}, T_{l}$ の項が含まれない式とな り,リンク系の影響を受けない制御系とすることがで きる。

$$
\begin{aligned}
& \left\{G_{m} s+G_{b} K_{b} s / K_{e}+K_{a} G_{c} G_{b}\right\} Q \\
& =K_{a} G_{b} G_{c} Q_{d}+T_{d}
\end{aligned}
$$

この場合, サーボ機構の特性方程式は, つぎのように なる.

$$
\begin{aligned}
& L\left(K_{t}^{\prime \prime} J_{m}+J_{l}\right) s^{3}+\left\{L\left(K_{t}^{\prime \prime} B_{m}+B_{l}\right)\right. \\
& \left.\quad+\left(R+K_{e} K_{q}\right)\left(K_{t}^{\prime \prime} J_{m}+J_{l}\right)\right\} s^{2} \\
& \quad+\left\{\left(R+K_{e} K_{g}\right)\left(K_{t}^{\prime \prime} B_{m}+B_{l}\right)\right. \\
& \left.\quad+K_{t}^{\prime \prime}\left(K_{b} K_{f}+K_{a} K_{e} K_{f} K_{d}\right)\right\} s \\
& \quad+K_{t}^{\prime \prime} K_{a} K_{e} K_{f} K_{p}=0
\end{aligned}
$$

ここで, $K_{t}^{\prime \prime}=1 /\left(1-K_{t}\right)$ であり, いま $K_{t}^{\prime \prime} \rightarrow \infty$ の極 限に括ける安定性を, Hurwitzの安定判別法を利用し て考察する. 各次数の項の係数は正なので, つぎの式 が安定条件を与える。

$$
\begin{gathered}
\left\{L\left(K_{t}^{\prime \prime} B_{m}+B_{l}\right)+\left(R+K_{e} K_{q}\right)\left(K_{t}^{\prime \prime} J_{m}\right.\right. \\
\left.\left.+J_{l}\right)\right\}\left\{\left(R+K_{e} K_{o}\right)\left(K_{t}^{\prime \prime} B_{m}+B_{l}\right)\right.
\end{gathered}
$$

$$
\begin{aligned}
& \left.+K_{t}^{\prime \prime}\left(K_{b} K_{f}+K_{a} K_{e} K_{f} K_{d}\right)\right\} \\
& >L\left(K_{t}^{\prime \prime} J_{m}+J_{l}\right) K_{t}^{\prime \prime} K_{a} K_{e} K_{f} K_{p}
\end{aligned}
$$

$K_{t}^{\prime \prime} \rightarrow \infty$ の極限においては,

$$
\begin{aligned}
& \left\{L B_{m}+\left(R+K_{e} K_{q}\right) J_{m}\right\}\left\{\left(R+K_{e} K_{q}\right) B_{m}\right. \\
& \left.\quad+\left(K_{b} K_{f}+K_{a} K_{e} K_{f} K_{d}\right)\right\} \\
& \quad>L J_{m} K_{a} K_{e} K_{f} K_{p}
\end{aligned}
$$

が安定条件を与えることになる（3.9)式には，負荷 変動を伴うリンク系の慣性および粘性抵抗の項がいっ さい含まれておらず，このサーボ機構の安定性がモー タ自身に対する従来のサーボ機構のそれと等価なとと を示している.

つぎに $K_{t}$ のとりうる範囲を考察したい. 理想的に は $K_{t}$ は 1 となるべきすのであるがサーボ機構のモデ ル化に伴う䛊差などにより，1 からずれる可能性があ りこの近傍での安定性について議論する. (3.7)式の 特性方程式を書き換えると，

$$
\begin{aligned}
& L K_{J} s^{3}+\left\{L K_{B}+\left(R+K_{e} K_{g}\right) K_{J}\right\} s^{2} \\
& \quad+\left\{\left(R+K_{e} K_{g}\right) K_{B}+\left(K_{b} K_{f}+K_{a} K_{e} K_{f} K_{d}\right)\right\} s \\
& \quad+K_{a} K_{e} K_{f} K_{p}=0
\end{aligned}
$$

亡なる. ここで,

$$
\begin{aligned}
& K_{J}=J_{m}+\left(1-K_{t}\right) J_{l} \\
& K_{B}=B_{m}+\left(1-K_{t}\right) B_{l}
\end{aligned}
$$

を用いた. 各次数の項の係数が正であるためには,つ ぎの条件が成り立てばよい.

$$
\begin{aligned}
& K_{J}>0 \\
& K_{B}>0
\end{aligned}
$$

このサーボ系が安定であるためには, さらにつぎの式 
が成り立つ必要がある.

$$
\begin{aligned}
& \left\{L K_{B} / K_{J}+\left(R+K_{e} K_{q}\right)\right\}\left\{\left(R+K_{e} K_{\vartheta}\right) K_{B}\right. \\
& \left.\quad+\left(K_{b} K_{f}+K_{a} K_{e} K_{f} K_{d}\right)\right\}>L K_{a} K_{e} K_{f} K_{p}
\end{aligned}
$$

（3.15)式は $K_{t}$ 亿依存するが，(3.13)，(3.14)式の条 件下で，どのような $K_{t}$ 亿対してあ(3.15)式が成立す るためには，つぎの条件を満たす必要がある.

$$
\begin{aligned}
& \left(R+K_{e} K_{q}\right)\left(K_{b} K_{f}+K_{a} K_{e} K_{f} K_{d}\right) \\
& \quad>L K_{a} K_{e} K_{f} K_{p}
\end{aligned}
$$

つまり，(3.15)式は(3.16)式が満たされるように $K_{p}$, $K_{d}$ を選ふことにより，自動的に満足される。したが って，(3.13)，(3.14)式がこのサーボ系の安定性の

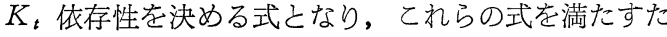
めには， $K_{t}$ について次式が成り立てばよい.

$$
K_{t}<1+\min \left(J_{m} / J_{l}, B_{m} / B_{l}\right)
$$

つまり, 本サーボ機構の場合, モデル誤差, トルクリ ップルなどにより $K_{t}$ が 1 からずれた場合であ安定性 は保たれる，その度合は，モータ系の負荷とリンク系 のそれとの比によって決まる．粘性項は，減速機の摩 擦などによりモータ系のほうがリンク系のそれより大 きいものと思われる，Jlは一般㑮動中に変化する ので定量的に判断することは難しいが，減速機付きア クチュエータでインピーダンスマッチングのとれたあ のの場合, $\left(J_{m} / J_{l}\right)$ は 1 の近傍であるとすると, 十分 安定性は保たれる。

\section{4. 実 験 結 果}

本サーボ機構の特徴を検討するために, 減速機付き 二関節アームを試作し，その制御実験を行った，試作 ロボットアームは，30 W の DC モータによりなる二 関節を有し，第 1 関節は平歯車による減速機が取り付 けられ，第 2 関節には八ーモニックドライブ方式が採 用されている．減速比は両関節とも $1 / 50$ である。卜 ルクセンサとしてはストレインゲージを用い，減速機

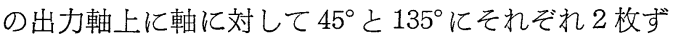
つ計 4 枚のゲージを貼った．第 1 ，第 2 リンクの長さ は，それぞれ $20 \mathrm{~cm}$ と $30 \mathrm{~cm}$ である. ロボットアー ムの先端には負荷を取り付けられるようになってお り，これにより慣性および負荷の変動実験を行うこと ができる，各モータは，ドライバ回路，D/A 変換装 置を介してパーソナルコンピニータに接続されてい る. 各関節の位置検出はエンコーダにより行われ，速 度は,タコメータ (第 1 関節) と $\mathrm{F} / \mathrm{V}$ 変換 (第 2 関節) により行われる．トルクセンサの出力は交流型の堌幅 器により約 700 (V/strain) に增幅され, A/D 変換装置 を用いてコンピュータに読み込まれる。 サーボコンピ
ユータとしては，16 ビットマイクロプロセッサを用 い， $2 \mathrm{~ms}$ のサンプリング周期でサーボ計算を行った.

慣性変動に対する効果を調へるるために，第 1 関節に 対する慣性を変えて，第 1 関節にステップ状の目標入 力を与え，その応答を測定した．実験は，リンクによ る慣性がゼロの場合之，それが $900 \mathrm{kgcm}^{2}$ の二種類 について行った．PD ゲインは，リンク慣性がゼロの 場合に制御系がクリティカルダンピングを示すように 決定された．乙のサーボ系に，トルクフィードバック を入れない場合といれた場合の応答を測定した結果 が，Fig. 4 亿示されている。

$\mathrm{PD}$ 制御の場合, 負荷にともなう慣性変動により, ステップ応答が負荷のない場合に比べ乱れ，わずかで はあるがオーバーシュートを示している。乙れにトル クフィードバックを加えることにより，ステップ応答 は，負荷のない場合のあのとほぼ同じ軌跡を示すよう になるととがわかる。

Fig. 5 亿動的干渉の影響に対する実験結果を示す. これは台座側の第 1 関節にステップ入力を与え，その ときの第 2 関節の位置制御性への影響を測定したもの である、第 2 関節は $0^{\circ}$ を目標角として位置制御され

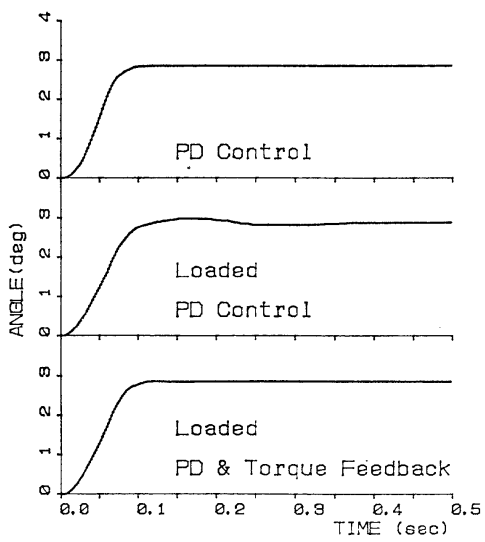

Fig. 4 Step response curves with load change

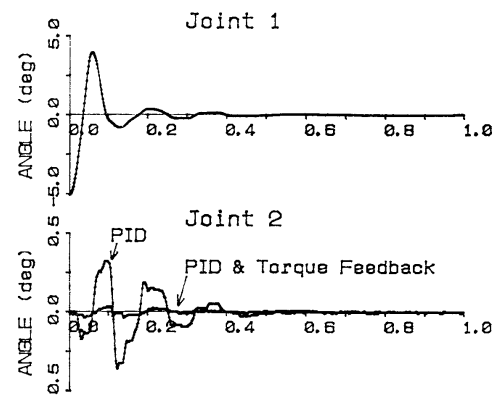

Fig. 5 Compensation of dynamic intervention between joints 


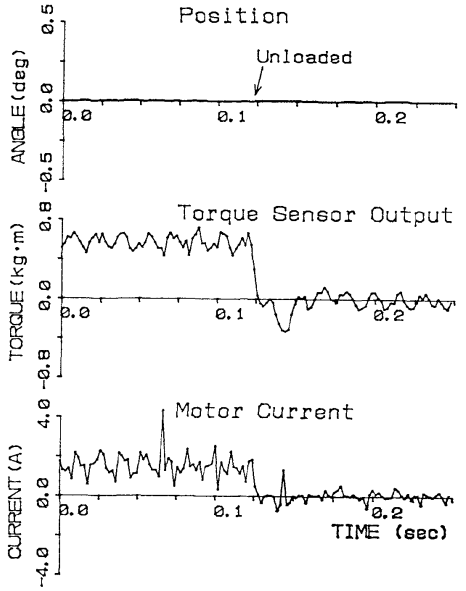

Fig. 6 Response for abrupt change in load

ている.トルクフィードバックにより動的干渉が補償 されており，外乱トルク $T_{d}$ の影響あ小さいととがわ かる.

トルクフィードバックを含むこのサーボ機構は手先 で把持した負荷に対して，モータの飽和限界内で理想 的なサーボ剛性を示すととができるすのと思われる. そこで，第 1 関節を一定角にフィードバック制御を行 い,そこに $2 \mathrm{~kg}$ の負荷をかけ，そのときの角度偏差 を測定した，さらに，ロボットが物体を掝んだり，放 したりする場合負荷の瞬間的な変動が予想され，その 場合の本サーボ機構の追従性, 安定性が問題となるす のと思われる. そこで, 先の奉験の負荷を急激に取り 除いて，その後の応答を調べた. Fig. 6 にその結果 を示した. PID 制御の場合との外乱負荷により $0.2^{\circ}$ 程度の位置偏差が生まれたが, 本制御法によりその偏 差はほぼゼロにでき，サーボ剛性がきわめて高いとと を示している.さらに除荷にともなうステップ状の負 荷変動に対しても, 正確に追従し位置偏差が生じない ことがわかる。

\section{7. 結 論}

減速機付きロボットアームへの応用を目標として， トルクセンサを用いた運動制御系の理論的解析, 実験 結果を示した. 動力学解析より, 減速機付きロボット アームの場合, 関節トルクセンサにより測定不可能な トルクが, 他の動的干渉によって発生するトルクに比 べわめて小さいことを明らかにした，安定性の解析 からは, トルクフィードバックゲインの変動に対して 本サーボ系は広い範囲にわたって安定性が保たれるこ とを示した．実験結果からは，慣性変動, 関節間の動 的干渉に対してそれらを無反応化し，より良い運動制
御を可能にした。 またワークの着脱時などに生じる 瞬間的な負荷変動に対しても，時間遅れを伴わずに正 しく応答した，さらに，本サーボ系のトルクフィード バックを含む実質的なサーボ剛性は，モータの飽和限 界内で理想的に高いととが示された。

これらにより，本制御法が減速機付きロボットアー ムのより正確な運動制御に有効であるととを示した。

本研究をすすめるにあたり, 電気通信大学佐藤公子 教授，山田達也氏に多大なる援助をいただきました.

ここに深く感謝いたします。

\section{参 考 文 献}

1) R.C. Paul: Modeling Trajectory Calculation and Servoing of a Computer Controlled Arm, A. I. Memo 177, Stanford Artificial Intelligence Lab., Stanford University, Sept. (1972)

2) J.Y.S. Luh, M.W. Walker and R. Paul: On-line Computational Scheme for Mechanical Manipulators, ASME Transaction, J. of Dynamical Systems, Measurements and Control, 102, 69/76 (1980)

3) T. J. Tarn, A. K. Bejczy, A. Ishidori and Y. Chen: Nonlinear Feedback in Robot Arm Control, Proc. of 23rd Conf. on Decision and Control, Las Vegas, NV, December, 736/751 (1984)

4) W. Khalil, J. F. Kleinfinger and M. Gautier: Reducing the Computational Burden of the Dynamic Models of Robots, IEEE 1986 Int. Conf. of Robotics and Automation, San Francisco, 525/531 (1986)

5) A. Izaguirre, M. Hashimoto, R. Paul and V. Hayward: A New Computational Structure for Real Time Dynamics, Technical Report MS-CIS-87 -107, University of Pennsylvania, CIS Dept., Moore School, Philadelphia (1987)

6) N. Kircanski : Real-Time Dynamics of Manipulation Robots, Colloquium at University of Pennsylvania, Philadelphia, December (1986)

7）小菅, 竹内，古田：関節トルクセンサを用いたロボット アームの制御, 第 26 回 SICE 学術講演会予稿集, 359/360 (1987)

8) 大㭇，平井, 池辺：負荷無反応形電気サーボ機構，計測 自動制御学会論文集, 21-10，74/79 (1985)

9) J.R. Hewit and N. Tan: Dynamic Coordination of Robot Movement, Proceedings of 4th CISM-IFToMM Symp. on Theory and Practice of Robots and Manipulators, 77/88 (1981)

10) M. Nakao, K. Ohnishi and K. Miyachi: A Robust Decentralized Joint Control Based on Interference Estimation, Proc. of IEEE 1987 Int. Conf. on Robotics and Automation, 326/331 (1987)

11) T.C. Hsia, T. A. Lasky and Y. Guo: Robust Independent Robot Joint Control: Design and Experimentation, Proc. of IEEE 1988 Int. Conf. on Robotics and Automation, 1329/1334 (1988)

12) 堀 洋一: 加速度制御形サーボ系の提案, 電学論研究開 発ノート, 107-D-12, p. 1531 (1987)

13）橋本 稔, P.R. Paul: アクチュエータマルチセンサ情報 の統合によるロボットの状態推定と故障検出, 計測自動 制御学会論文集， 24-3，72/79（1988） 